\title{
Mechanical Properties of
} Strontium-Hardystonite-Gahnite Coating Formed by Atmospheric Plasma Spray

\author{
Duy Quang Pham ${ }^{1}\left(\mathbb{D}\right.$, Christopher C. Berndt ${ }^{1} \mathbb{D}$, Ameneh Sadeghpour $^{2}$, Hala Zreiqat ${ }^{3}$, \\ Peng-Yuan Wang ${ }^{4,5}$ and Andrew S. M. Ang 1,*(D) \\ 1 Department of Mechanical and Production Design Engineering, Surface Engineering for Advanced \\ Materials (SEAM), Swinburne University of Technology, Hawthorn, VIC 3122, Australia; \\ dqpham@swin.edu.au (D.Q.P.); cberndt@swin.edu.au (C.C.B.) \\ 2 Department of Innovation, Quality Assurance and Regulatory Affairs, Allegra Orthopaedics Limited, \\ Sydney, NSW 2066, Australia; Ameneh.Sadeghpour@allegraorthopaedics.com \\ 3 School of Aerospace, Mechanical and Mechatronic Engineering, Innovative Bioengineering, \\ The University of Sydney, Sydney, NSW 2006, Australia; hala.zreiqat@sydney.edu.au \\ 4 Center for Human Tissues and Organs Degeneration, Institute of Biomedicine and Biotechnology, \\ Shenzhen Institutes of Advanced Technology, Chinese Academy of Sciences, Shenzhen 518055, China; \\ pengyuanwang@swin.edu.au \\ 5 Department of Chemistry and Biotechnology, Swinburne University of Technology, Victoria 3122, Australia \\ * Correspondence: aang@swin.edu.au; Tel.: +61-3-9214-4964
}

Received: 1 October 2019; Accepted: 12 November 2019; Published: 15 November 2019

\begin{abstract}
In this work, we measured the mechanical properties and tested the cell viability of a bioceramic coating, strontium-hardystonite-gahnite ( $\mathrm{Sr}-\mathrm{HT}-\mathrm{G}, \mathrm{Sr}-\mathrm{Ca}_{2} \mathrm{ZnSi}_{2} \mathrm{O}_{7}-\mathrm{ZnAl}_{2} \mathrm{O}_{4}$ ), to evaluate potential use of this novel bioceramic for bone regeneration applications. The evaluation of Sr-HT-G coatings deposited via atmospheric plasma spray (APS) onto Ti-6Al-4V substrates have been contrasted to the properties of the well-known commercial standard coating of hydroxyapatite (HAp: $\left.\mathrm{Ca}_{10}\left(\mathrm{PO}_{4}\right)_{6}(\mathrm{OH})_{2}\right)$. The Sr-HT-G coating exhibited uniform distribution of hardness and elastic moduli across its cross-section; whereas the HAp coating presented large statistical variations of these distributions. The Sr-HT-G coating also revealed higher results of microhardness, nanohardness and elastic moduli than those shown for the HAp coating. The nanoscratch tests for the Sr-HT-G coating presented a low volume of material removal without high plastic deformation, while the HAp coating revealed ploughing behaviour with a large pileup of materials and plastic deformation along the scratch direction. Furthermore, nanoscanning wear tests indicated that Sr-HT-G had a lower wear volume than the HAp coating. The Sr-HT-G coating had slightly higher cell attachment density and spreading area compared to the HAp coating indicating that both coatings have good biocompatibility for bone marrow mesenchymal stem cells (BMSCs).
\end{abstract}

Keywords: Sr-HT-Gahnite; hydroxyapatite; atmospheric plasma spray; nanoindentation; mechanical properties

\section{Introduction}

Substitutional materials for bone have been active research areas since the 1970s and ceramics account for the majority of these replacements [1]. These bioceramics include three groups: (i) bioinert, (ii) bioactive, and (iii) biodegradable or bioresorbable ceramics [2]. In brief, bioinert ceramics have no or very little interaction with surrounding tissues when they are placed into the host body. However, bioactive ceramics can form chemical bonds with surrounding bones and these biodegradable 
ceramics are gradually replaced by endogenous tissues after implantation into the host body [2]. Calcium phosphate ceramics are commonly used for bioactive applications of bone tissue repair and augmentation because of their similar chemical composition to minerals in bone [3].

Hydroxyapatite (HAp: $\left.\mathrm{Ca}_{10}\left(\mathrm{PO}_{4}\right)_{6}(\mathrm{OH})_{2}\right)$ is the most widely accepted biocompatible and bioactive calcium phosphate ceramic with respect to tissues [4]. In bulk form, HAp presents excellent physio-chemical properties as a bioceramic; however, these attributes are deteriorated by an intrinsic brittleness, low impact resistance and low tensile strength limit when implanted for load-bearing applications [5]. One method to improve the mechanical properties while maintaining the bio-adaptive properties is by forming a HAp coating onto a metallic biomaterial [6] in applications where the bioceramic is under compressive loads. Implants that are based on a HAp coated metal can provide excellent bioactivity and biocompatibility to the host bone, while retaining the good strength and ductile properties of the metallic substrate [4].

Although a HAp coating on a metallic substrate has demonstrate good clinical and commercial outcomes [7], the demand for improving the mechanical properties of a HAp coating is still imperative. For example, the high-velocity suspension flame spray method has been used to coat a nano-structured HAp/Ti composite onto 316L stainless steel (SS) substrates [8], and the suspension plasma spray (SPS) method has been employed to produce a nano-diamond reinforced hydroxyapatite composite coating onto a titanium substrate [9]. The advantages of these two methods using suspension-based feedstock are the ability to deposit materials in submicron sizes or create new composite materials for thermal spray coating [10]. However, the feedstock feeder system and torch re-configurations are required in order to adapt to the suspension feedstock, which is considered costly and complicated. Using flame spray as a coating method has been the preferred method in the last decades because it is a low cost system, portable and easy to use, but a high porous coating with oxidation and low jet temperature with low particle velocity are the major concerns of the flame spray [11]. In contrast, atmospheric plasma spray (APS) is the most commonly used coating method for orthopedic implants and has been approved by Food and Drug Administration [12]. The APS technology allows high jet temperature and velocity so it can be used to create a denser coating with the same material [11].

Introducing substitute bioceramics that may enhance mechanical properties and biocompatibility is an alternative approach addressed in this research. It is known that silicon is a trace element in the human body that occurs naturally; e.g., $100 \mathrm{ppm}$ in bone and 200-600 ppm in cartilage and other connective tissues [13]. Silicon performs as a biological linkage to form the structure of connective tissues and engages in the process of biomineralization to promote bone growth [14]. The development of Si-containing biomaterials is an active area of research such as developing bioglasses and Si-doped bioceramics [15]. Calcium silicate (Ca-Si) based ceramics, in particular $\mathrm{CaSiO}_{3}$ and $\mathrm{Ca}_{2} \mathrm{SiO}_{4}$ are currently used in orthopaedic implants since they are bioactive materials that induce a bond with bone to form an apatite layer and promote the bone growth [16-18]. However, the main concerns of these bioceramics are low chemical stability with a high ionic dissolution and high degradation rates; This instability affects the mechanical strength and osseointegration at high $\mathrm{pH}$ levels [19], i.e., $\mathrm{pH}=8.34$ after soaking $\mathrm{CaSiO}_{3} 25$ days in a simulated body fluid (SBF) solution [20]. One method to control the dissolution is by incorporating metal ions into Ca-Si based bioceramics, which often uses zinc or/and strontium metals [19]. Zinc supports bone formation, increases bone protein and alkaline phosphatase activity in osteoblasts differentiation and mineralization, and enhances cell proliferation osteoconductivity [21]. Strontium is associated with bone through two main mechanisms which are (i) incorporation of Sr into bone crystal lattice-surface exchanging and (ii) ionic exchange with bone-ionic substitution [19].

Therefore, strontium doped hardystonite $\left(\mathrm{Sr}-\mathrm{Ca}_{2} \mathrm{ZnSi}_{2} \mathrm{O}_{7}\right)$, named $\mathrm{Sr}-\mathrm{HT}$, is a Ca-Si based ceramic that incorporates zinc and strontium, and which shows improvements in cellular activity and chemical stability compared with $\mathrm{CaSiO}_{3}$ [19]. Sr-HT in the form of a scaffold (pore interconnectivity: 99\%, pore size: 300 to $500 \mu \mathrm{m}$, and porosity: $78 \%$ ) has shown exceptional bioactivity as a scaffold to repair large-sized bone defects. It presented a high compressive strength of $2.16 \pm 0.52 \mathrm{MPa}$, which is a 
favorable property for load-bearing applications. By mixing 80 wt \% Sr-HT with $\sim 20 \mathrm{wt} \%$ gahnite $\left(\mathrm{ZnAl}_{2} \mathrm{O}_{4}\right)$ [22], the Sr-HT-G ceramic had high fracture toughness and compressive strength properties that were superior to those of cortical bone [22]. A Sr-HT-G scaffold (pore interconnectivity: 100\%, pore size: $500 \mu \mathrm{m}$, and porosity: $85 \%$ ) presented higher compressive strength of $4.1 \pm 0.3 \mathrm{MPa}$ than solely Sr-HT [22]. Sr-HT-G scaffolds are able to repair the large bone defects, which are outstanding against the $\beta$-tricalcium phosphate/hydroxyapatite (TCP/HA) scaffolds [22]. The Sr-HT-G scaffolds can promote the attachment of adipose derived stem cells and the alkaline phosphatase activity of these cells when contrasting with $\beta$-TCP/HA scaffolds [23]. These scaffolds also enhance the migration, proliferation and differentiation of human umbilical vein endothelial cells without adverse effect on viability cells [23]. The 3D-printed Sr-HT-G scaffolds in the study of Li et al. have shown a significant effect in repairing bone defects in sheep tibia for 3 and 12 months, where the bone formation significantly bridged the defects [24].

In this study, the atmospheric plasma spray (APS) technique was employed to deposit Sr-HT-G powders onto Ti-6Al-4V substrates in order to evaluate the possibility of using this coating for applications of orthopedic implants. Commercial hydroxyapatite powders were used to produce control samples. The study compares the mechanical and chemical properties of the Sr-HT-G to HAp coating and includes: (i) surface characteristics of the coatings, (ii) chemical analysis and phases of coatings, (iii) Vickers microhardness, (iv) distribution of hardness and elastic moduli via nanoindentation, (v) nanoscratch and nanowear behavior, and (vi) stem cell culture study.

\section{Materials and Methods}

\subsection{Powder Preparation}

The Sr-HT-G powders were prepared by Allegra Orthopaedics Limited (Sydney NSW, Australia) following the method that is described in the study of Roohani-Esfahani et al. [22]. Briefly, Hardystonite $\left(\mathrm{Ca}_{2} \mathrm{ZnSi}_{2} \mathrm{O}_{7}\right)$ powders were prepared through the sol-gel method from tetraethyl orthosilicate ("TEOS" of formula $\left.\left(\mathrm{C}_{2} \mathrm{H}_{5} \mathrm{O}\right)_{4} \mathrm{Si}\right)$, zinc nitrate hexahydrate $\left(\mathrm{Zn}\left(\mathrm{NO}_{3}\right)_{2} \cdot 6 \mathrm{H}_{2} \mathrm{O}\right)$ and calcium nitrate tetrahydrate $\left(\mathrm{Ca}\left(\mathrm{NO}_{3}\right)_{2} \cdot 4 \mathrm{H}_{2} \mathrm{O}\right)$. Then, strontium ions (from $\left.\mathrm{Sr}\left(\mathrm{NO}_{3}\right)_{2}, 5 \mathrm{wt} \%\right)$ were added to substitute calcium ions to form Sr-HT. Finally, alumina $\left(\mathrm{Al}_{2} \mathrm{O}_{3}\right)$ powder $(15 \mathrm{wt} \%)$ was added into the $\mathrm{Sr}-\mathrm{HT}$ system. Initially, the Sr-HT-G powder was of submicrometer size and was not suitable for APS due to poor powder flow characteristics. The flow behavior was improved by initially mixing the Sr-HT-G powder with $5 \mathrm{wt} \%$ polyvinyl alcohol (PVA, Sigma Aldrich, St. Louis, MO, USA). This mixture was consolidated into bulk form by heating in an oven at $70{ }^{\circ} \mathrm{C}$ for $24 \mathrm{~h}$. The consolidated mass was then ground in a mortar and pestle before sieving to $45-106 \mu \mathrm{m}$. The HAp powder, from Medicoat SAS (Etupes, France), exhibited particle sizes of 45 to $125 \mu \mathrm{m}$.

\subsection{Plasma Coating Set Up and Operation}

A Metco 9MB plasma torch with a 7 mm-Metco GH nozzle (Sulzer Metco, Westbury, NY, USA) was used to deposit Sr-HT-G and HAp powders onto Ti-6Al-4V substrates. The coatings were deposited at room temperature, using a six-axis robot (YR-SK16-J00; Motoman Robotics, Miamisburg, $\mathrm{OH}, \mathrm{USA}$ ) to control the torch position with the velocity of between 100 to $150 \mathrm{~mm} / \mathrm{s}$. The same coating parameters were applied for both Sr-HT-G and HAp powders (Table 1).

Table 1. Setup parameters for plasma coating of Sr-HT-G and HAp powders.

\begin{tabular}{cc}
\hline Parameters & Value \\
\hline Power $(\mathrm{kW})$ & 21 \\
Primary gas flow, Ar (slpm) & 30 \\
Secondary gas flow, $\mathrm{H}_{2}(\mathrm{slpm})$ & 5 \\
Powder carrier gas flow, Ar (slpm) & 9 \\
Number of torch passes & 5 \\
Stand-off distance (mm) & 90 \\
\hline
\end{tabular}




\subsection{Coating Characterisations}

Phase compositions of powders and coatings are analysed by the Bruker D8 Advance XRD system (Bruker Corp., Billerica, MA, USA) with $\mathrm{Cu} \mathrm{K} \alpha$ radiation. The XRD system operates at $40 \mathrm{kV}$ and $30 \mathrm{~mA}$ to scan over the range of $20^{\circ}-70^{\circ}$ with a step size of $0.08^{\circ}$ and $2 \mathrm{~s}$ of dwell time. The XRD results were indexed using Diffracplus EVA software (EVA V5, Bruker Corp., Billerica, MA, USA) and then compared with database PDF2018-PDF-2-Release 2018 RDB from the International Center for Diffraction Data (ICDD, Newtown Square, PA, USA). The crystallinity level is calculated based on the intensity of peaks, which is described in Equation (1), where $A_{\mathrm{c}}$ and $A_{\mathrm{a}}$ are total intensity of peaks and total intensity of amorphous phase [25].

$$
\text { Crystallinity }=A_{\mathrm{c}} /\left(A_{\mathrm{c}}+A_{\mathrm{a}}\right) \times 100 \%
$$

where $A_{\mathrm{c}}$ and $A_{\mathrm{a}}$ are total intensity of peaks and total intensity of amorphous phase.

Chemical analysis of coatings was conducted using an X-ray photoelectron spectrometer (XPS) with a Kratos Axis Nova system (Kratos Analytical, Manchester, UK) and Raman microspectroscopy with an In-Via Raman Microscope system (Renishaw ${ }^{\circledR}$, Gloucestershire, UK). The XPS system has the X-ray source of $\mathrm{Al} \mathrm{K \alpha}$ with $\mathrm{h} v=1486.69 \mathrm{eV}$ that operates at $150 \mathrm{~W}$. XPS data were analysed by CasaXPS software (Version 2.3.15, CASA Software Ltd., Cheshire, UK) after a Shirley background subtraction with the correction of binding energy for carbon at $285 \mathrm{eV}$. The XPS characterisation was done on the as-sprayed samples, which is how it would be used in actual orthopedic applications. Raman microspectroscopy used $785 \mathrm{~nm}$ laser wavelength with $10 \%$ of the $150 \mathrm{~W}$ laser power and $10 \mathrm{~s}$ for exposure time. High-resolution electron micrographs were obtained using a field emission SEM (SUPR 40 VP, Carl Zeiss, Oberkochen, Germany) at $5 \mathrm{kV}$. In all cases, the coating surfaces were cleaned by ethanol and then dried by compress air. After that, the samples were place in a vacuum environment till it underwent characterisation.

Coatings were cut and prepared following ASTM E1290-03 "Standard Guide for Metallographic Preparation of Thermal Sprayed Coatings" [26] to get cross sections of coatings for analysis. A Vickers microhardness tester (Micromet 2103 Microhardness tester, BUEHLER, Lake Bluff, IL, USA) was setup to perform the microhardness test on cross sections of coatings at the load of $300 \mathrm{gf}$ and dwell time of $15 \mathrm{~s}$. Forty readings was recorded on each sample and the Weibull distribution analysis was performed to analyse coating properties and reliability. Surface roughness, $R_{\mathrm{a}}$, was measured using a portable surface roughness tester SJ-210 (Mitutoyo, Kawasaki, Japan) with a $2 \mu \mathrm{m}$ stylus diameter together with a 3D optical profiler system (Bruker Corporation, Billerica, MA, USA).

A nanoindenter (Hysitron TI Premier, Bruker, Eden Prairie, MN, USA) with a Berkovich diamond tip was used to perform the nanohardness and elastic moduli. A cono-spherical $1 \mu \mathrm{m}$ diameter diamond tip was used in the nanoindentation system to performe nanoscratch and nanowear tests. The resolutions of the nanoindentation system are $1.0 \mathrm{nN}$ and $0.006 \mathrm{~nm}$ for the applied load and tip displacement, respectively. The distributions of hardness and elastic moduli of coatings were investigated using accelerated property mapping (XPM) with the support of the scanning probe microscopy (SPM) method. The nanoindentation test were performed following the testing procedure, which was described in the previous study of Pham et al. [27]. Briefly, the tests were done on areas of $30 \times 30 \mu \mathrm{m}^{2}$ with 400 indents in each area (1.5 $\mu \mathrm{m}$ gap between indents). Fifteen areas was selected along the cross section of each coating, and the applied loads were from 500 to $3000 \mu \mathrm{N}$. Elastic moduli and hardness were determined by measuring penetration depths after indenting at the applied load using the Oliver-Pharr method [28].

Nanoscratch tests were performed at the loads from 1000 to $2000 \mu \mathrm{N}$ with the scratch length of $10 \mu \mathrm{m}$. Nanowear test was conducted by applying a load of $200 \mu \mathrm{N}$ onto the area of $10 \times 10 \mu \mathrm{m}^{2}$ and scanned over the section three times for each selected areas at the scanned frequency of $0.8 \mathrm{~Hz}$. The wear volumes were calculated by measuring the different heights between the before and after of the scanned areas, and multiplying the height difference with the scanning size. The results from 
nanoscratch and nanowear tests were analysed by TriboView software (Version 10.0.0.2, Hysitron TI Premier, Bruker, Eden Prairie, MN, USA).

\subsection{Stem Cell Culture}

Human bone marrow mesenchymal stem cells (BMSCs) were purchased from Cyagen Biosciences (HUXMF-0101, Suzhou Inc., Suzhou, China) at passage 2 and maintained in a complete growth media (HUXMF-90011, Cyagen Bioscience). The complete growth media of BMSC was composed of $440 \mathrm{~mL}$ basal medium, $50 \mathrm{~mL}$ fetal bovine serum, $5 \mathrm{~mL}$ glutamine, $5 \mathrm{~mL}$ penicillin-streptomycin. It was used as purchased without the addition of extra growth factors. The growth media is only used for BMSC maintenance. For the biocompatibility test, cells were seeded at a density $5000 \mathrm{cells} / \mathrm{cm}^{2}$ and fixed after 24 h. Phalloidin-Rhodamine B (cat\# P1961, Sigma, Tokyo, Japan) and DAPI (cat\# D1306, Sigma) were employed for F-actin filament and cell nucleus staining, respectively. Immunostained samples were washed thoroughly and examined under an inverted fluorescence microscope (IX73 Olympus, Tokyo, Japan) at 20 magnification. Cell density (cells $\left./ \mathrm{mm}^{2}\right)$ and cell spreading area $\left(\mu \mathrm{m}^{2}\right)$ on three different substrates including as-received Ti, HAp coating, and Sr-HT-G coating, which were quantitatively analysed based on the obtained images. The cell number and cell spreading area were analysed from the DAPI stained and F-actin stained cells via NIH ImageJ software (Version 1.52). DAPI stained images were processed via threshold color and the number of nuclei was automatically determined via the plugin of cell counter in Image J software (Version 1.52); Similarly, F-actin stained images were processed via threshold color and the occupied area was automatically measured via Image J software (Version 1.52).

\section{Results and Discussions}

\subsection{Feedstock Morphology}

Morphologies of Sr-HT-G (after of mixing with PVA, consolidating, grinding and sieving) and HAp powders are indicated in Figure 1a,b, respectively. Sr-HT-G powders were manually ground and sieved so the powders are described as angular and blocky, while HAp powders are spherical-like shape. The morphology of Sr-HT-G powders provide higher ratio of surface area to volume than that of HAp powders, which can lead to a better degree of heating in plasma plumes [29]. HAp may present better flow transportation characteristics than Sr-HT-G because spherical powders are preferable morphology in plasma spray. These HAp particles can easily enter into the center of the plasma plume to be well deposited, while Sr-HT-G powders may not be injected ideally into the plasma flame due to irregular sizes [11,29].
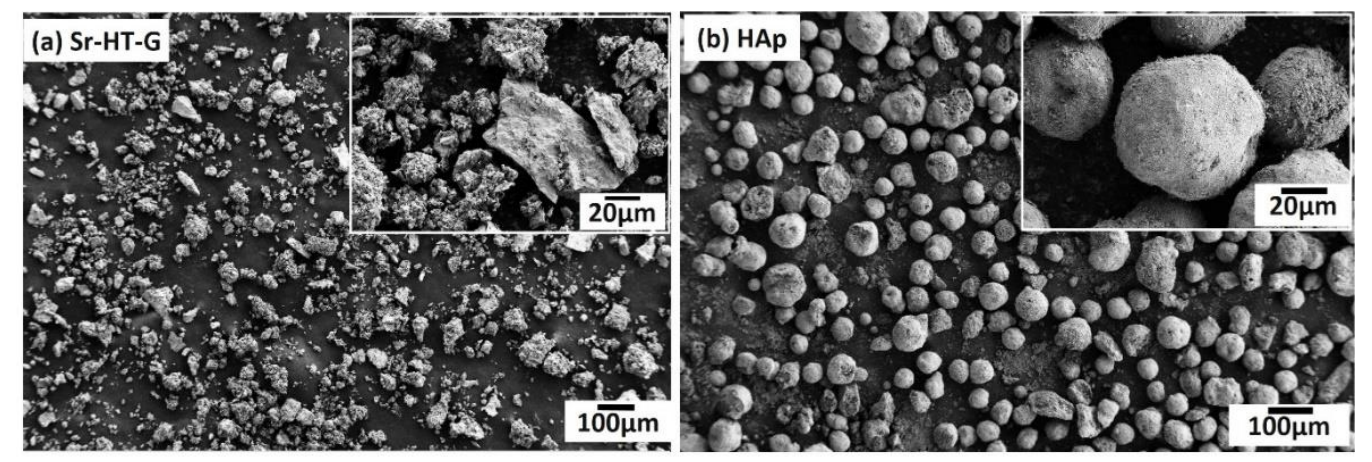

Figure 1. Feedstock morphology of strontium-hardystonite-gahnite (Sr-HT-G) (a) and hydroxyapatite (HAp) (b). 


\subsection{Coating Surface Analysis}

\subsubsection{Phase Compositions}

Figure 2 presents the XRD results of powders and coatings for Sr-HT-G and HAp. Sr-HT-Ga powders consist of two distinct phases in Figure 2a, which are Sr-HT (PDF 01-072-1603) and gahnite (PDF 01-070-8181). The gahnite phase in starting powders is formed by the reaction between zinc in Sr-HT and alumina during the sintering process at high temperatures to produce powders [22]. Similar to the staring powders, the coating of Sr-HT-G also presents two phases, which are Sr-HT and gahnite. The peaks of Sr-HT-G coating are significantly less sharp and are broaden after the plasma coating, which indicate the reduction in the level of crystallinity. However, there is no new peaks formed in the Sr-HT-G coating, but they are slightly shifted in the peaks of the coating comparing with its powders. The reason for the peak shifts could be the internal or residual stress after coating, which causes the change in lattice parameters. On the other hand, HAp powders present high purity with phase of HAp, but its coating presented the phase of $\mathrm{Ca}_{10}\left(\mathrm{PO}_{4}\right)_{6}(\mathrm{OH})_{2}(\mathrm{PDF}$ 00-064-0738) and a new phase of tricalcium phosphate-TCP $\left(\mathrm{Ca}_{3}\left(\mathrm{PO}_{4}\right)_{2}\right)(\mathrm{PDF}$ 01-072-7587) in Figure $2 \mathrm{~b}$. This new phase $\mathrm{TCP}$ was formed by the reaction of HAp in the high temperature region of plasma plume [30].
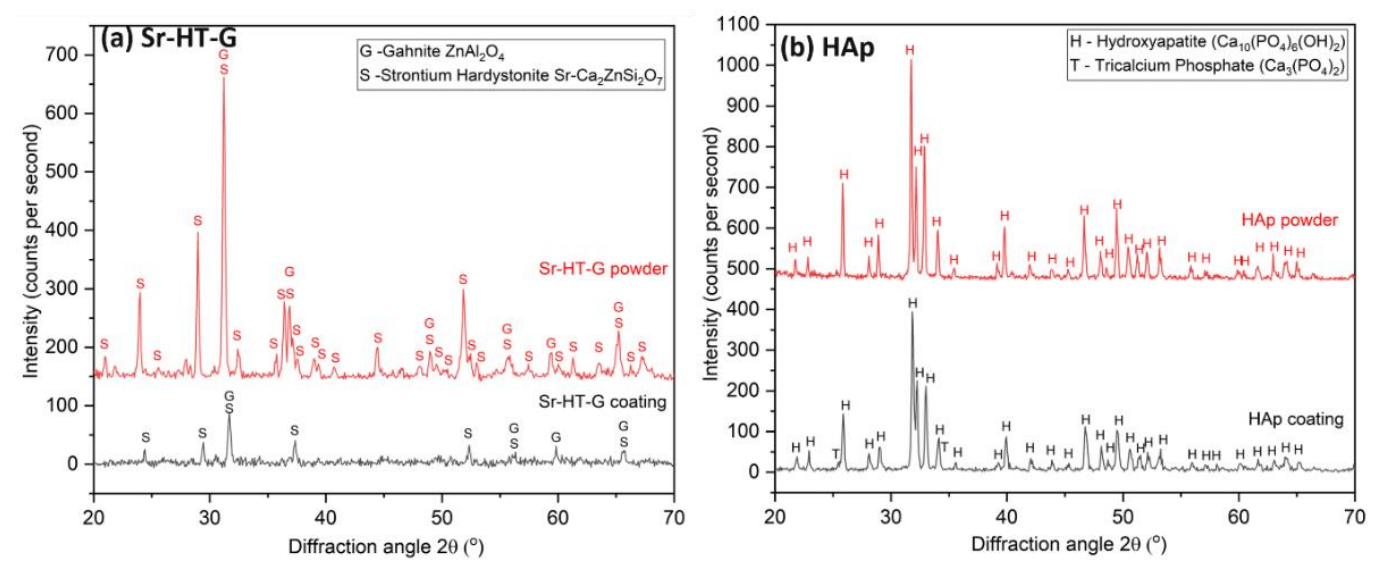

Figure 2. XRD results of Sr-HT-G powder and coating (a) and HAp powder and coating (b).

Both coatings illustrate lower intensity levels or lower crystallinity compared with their starting powders. Significant lower intensity of the peaks in a coating comparing to its starting powder can be seen in the result of Sr-HT-G, of which the level of crystallinity from Equation (1) are 74.6\% and 32.7\% for powders and the coating, respectively. On the other hand, levels of crystallinity in HAp powders and coating are not significantly different, which are $84.8 \%$ and $75.5 \%$ for powders and the coating, respectively. The lower crystallinity in the coating is a feature of the plasma process, which feedstock are exposed and heated by a $10,000{ }^{\circ} \mathrm{C}$ plasma flame, then rapidly cooled at about $10^{6}$ degrees per second, where the feedstock do not have enough time to recrystallize [29]. It can be seen that the Sr-HT-G coating presents lower levels of crystallinity than that in the HAp coating. Sr-HT-G is a Ca-Si ceramic with the sorosilicate $\left(\mathrm{Si}_{2} \mathrm{O}_{7}\right)$ group that has a more intricate crystalline structure, so the process of recrystallize will be more complex than that of HAp [31]. In contrast, HAp powders with larger particle sizes are well deposited with a larger quantity in the coating because they are fed into the center of the plasma flame. As the result, a greater amount of bulk crystalline can be found in the coating, which leads to a higher percentage of crystallinity [32].

\subsubsection{XPS on Coating Surfaces}

Figure 3a presents the XPS analysis result of Sr-HT-G coating with the presence of $\mathrm{Sr}, \mathrm{Ca}, \mathrm{Zn}$, $\mathrm{Si}, \mathrm{O}, \mathrm{Al}$ on the coating surface. Two peaks of $\mathrm{Zn}$ in the spectrum are $\mathrm{Zn} 2 p$ and $\mathrm{Zn} 2 p 1 / 2$ at 1022.9 and $1045.9 \mathrm{eV}$, respectively. Furthermore, the presenting of the peaks $\mathrm{Al} 2 p$ at $74.0 \mathrm{eV}$ and $\mathrm{Al} 2 s$ at 
$119.0 \mathrm{eV}$ together with the peak $\mathrm{O} 1 \mathrm{~s}$ at $531.5 \mathrm{eV}$ indicates the formation of $\mathrm{ZnAl}_{2} \mathrm{O}_{4}$ on the coating surface [33,34]. In a high-resolution scan presented in Figure 3c, Si presented the peak of $\operatorname{Si} 2 p$ at $102 \mathrm{eV}$, which refers to the presence of a silicate group [35]. This silicate group is $\mathrm{Si}_{2} \mathrm{O}_{7}$, which is in the structure of $\mathrm{Sr}-\mathrm{HT}$. Formation of $\mathrm{Sr}-\mathrm{HT}$ and gahnite phases are further supported by results from the analysis in XRD. The Sr-HT and gahnite composite ceramic has shown an improvement in biocompatibility and bioactivity, which has been evaluated by its capability in osteoconduction and osteoinduction [36]. Thus, a plasma coating with the present of $\mathrm{Sr}-\mathrm{HT}$ and gahnite phases will potentially produce good biocompatibility and bioactivity.

Chemical elements on the surface of HAp coating under XPS analysis are shown in Figure $3 \mathrm{~b}$. The surface of HAp coating consists of $\mathrm{Ca}, \mathrm{P}$, and $\mathrm{O}$ as the main elements in its starting powders. The peak of $\mathrm{P} 2 p$ is $132.8 \mathrm{eV}$, while the peak of $\mathrm{O} 1 s$ is $530.8 \mathrm{eV}$. This result indicates the present of the $\mathrm{PO}_{4}{ }^{3-}$ group [35], which is in the structure of hydroxyapatite $\mathrm{Ca}_{10}\left(\mathrm{PO}_{4}\right)_{6}(\mathrm{OH})_{2}$. Calcium has four peaks, which are $\mathrm{Ca} 2 s, \mathrm{Ca} 2 p, \mathrm{Ca} 3 s$, and $\mathrm{Ca} 3 p$. The Ca $2 s$ presents a peak at $438.6 \mathrm{eV}$, while the Ca $2 p$ consists of a doublet with values of 346.9 and $350.4 \mathrm{eV}$ for Ca $2 p 3 / 2$ and Ca $2 p 1 / 2$, respectively. The peaks of $\mathrm{Ca} 3 i$ and $\mathrm{Ca} 3 p$ are 44.0 and $25.3 \mathrm{eV}$ that are illustrated in Figure $3 \mathrm{~d}$. The results of calcium peaks indicate the formation of $\mathrm{Ca}_{3}\left(\mathrm{PO}_{4}\right)_{2}$ [37]. These HAp phases have been shown to support the in vitro and in vivo formation of bone.
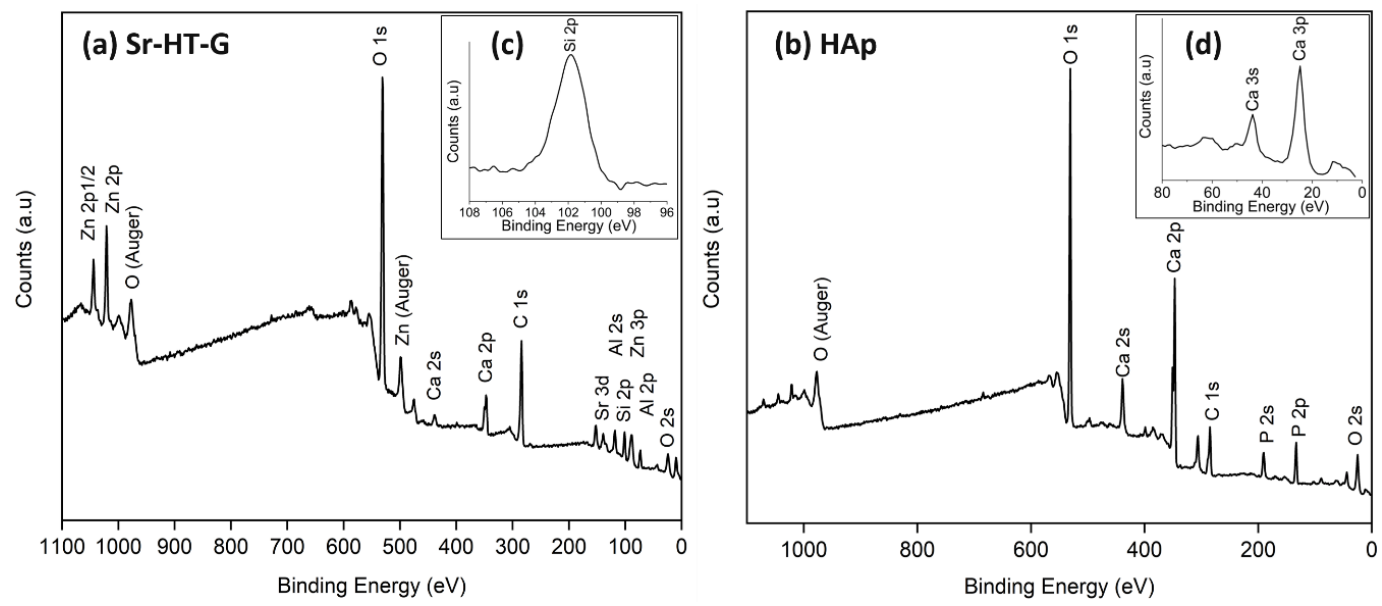

Figure 3. XPS analysis of Sr-HT-G coating (a) and HAp coating (b). The peaks of Si $2 p$ (c), Ca $3 i$ and Ca $3 p(\mathbf{d})$.

\subsubsection{Morphologies of Coating Surfaces}

Surfaces of the Sr-HT-G and the HAp coatings are shown in Figure 4a,b, respectively, where both coatings show well-melted splats. However, the Sr-HT-G coating shows more uniform surface morphology with spherical-like splat shapes, while HAp coating presents irregular splats with a big splash at the rims. Furthermore, some fragmentations can be found within splats of the HAp coating, whilst the Sr-HT-G coating shows more consistent structure on the surface with more uniform splats. Under the melting and re-solidify processes in APS, well-melted splats or partially melted particles will spread onto the substrate and form layers of splats [38]. Molten particles of Sr-HT-G show higher spreading ability than the HAp, which could be closely related to its viscosity characteristics and eventually reveals more regular Sr-HT-G splats [39]. 


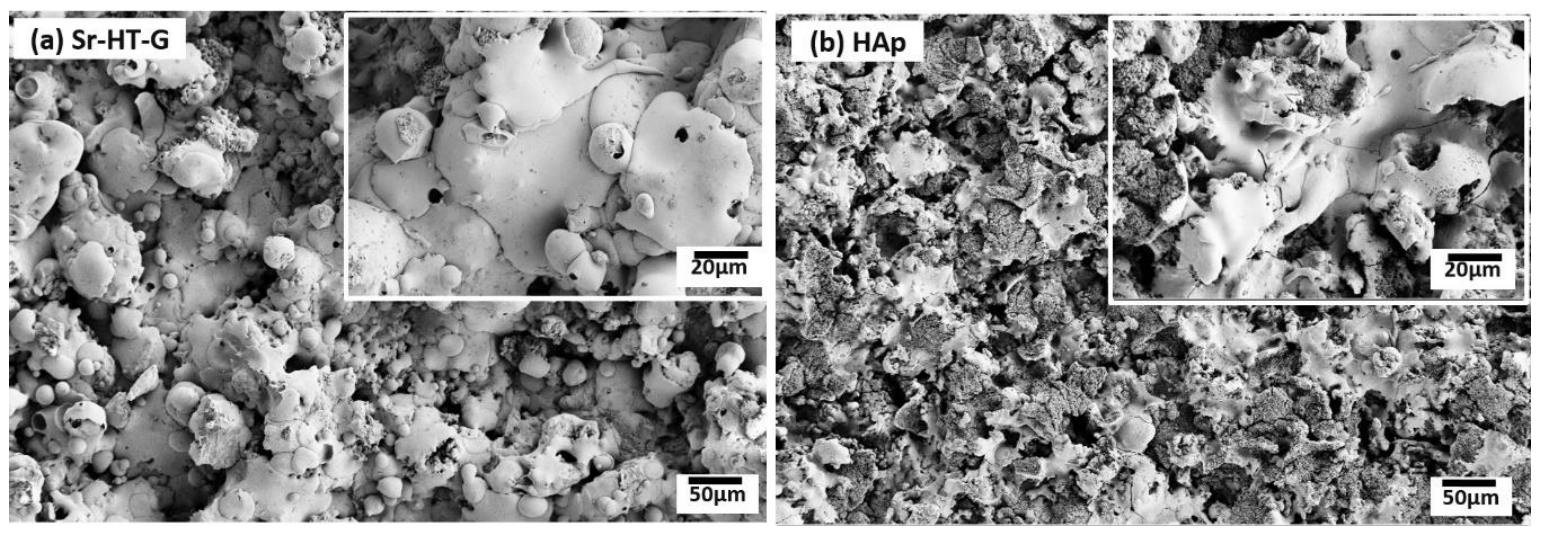

Figure 4. SEM of coating surfaces of Sr-HT-G (a) and HAp (b).

\subsection{Coating Cross Section Analysis}

\subsubsection{Coating Microstructures}

Figure 5 indicates the microstructure of the Sr-HT-G and the HAp coatings at cross sections. Both coatings present features of thermal spray coating including cracks, pores, and unmelted particles [38]. Different phases can be found in the HAp coating as the result of different contrasts, which are shown in bright gray and dark gray. The amorphous phase is easily removed during the polishing process, which causes the height to be lower than the crystalline areas. As the result, the amorphous phase appears to be darker. This observation has been re-confirmed with Raman spectroscopy. Similar results have been presented in the works of Gross et al. [30,40]. However, there is not much difference in contrast of phases in the Sr-HT-G coating as its microstructure presents a similar contrast to the source of ignition during the SEM process. It can be seen that the Sr-HT-G coating has less cracks in microstructure, while the HAp coating presents more cracks. Moreover, due to the reaction of alumina with zinc in Sr-HT, a more uniform structure is formed [36], where the Sr-HT-G coating has a denser structure and a more consistent microstructure compared with the HAp coating. Less pores in the structure of the Sr-HT-G coating could come from the larger distribution of powder sizes, where different sizes of Sr-HT-G splats are likely to fill up the pores in the microstructure during the process of deposition [11]. In addition, the interface of coating-substrate in the Sr-HT-G coating is quite consistent with crack-free features, while the HAp coating shows minor cracks at the coating-substrate interface.
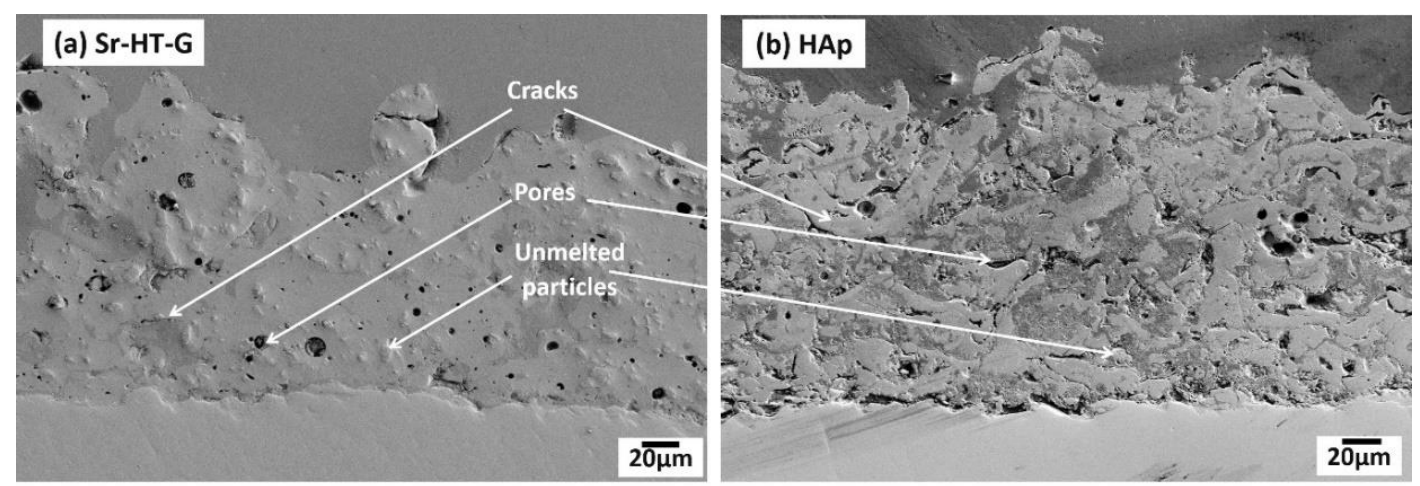

Figure 5. Microstructure of Sr-HT-G (a) and HAp (b) on coating cross section.

\subsubsection{Vickers Microhardness}

The results of Vickers microhardness are shown in Figure 6, where the hardness of the Sr-HT-G and the HAp coatings are $330.4 \pm 54.4$ HV300 and $120.2 \pm 24.3$ HV300, respectively. Vickers microhardness in the coating of Sr-HT-G is significantly high due to the addition of $\mathrm{Zn}$ into the Ca-Si structure [19,21], 
which is almost triple the hardness of the HAp coating. In addition, the formation of a glass phase between $\mathrm{Sr}-\mathrm{HT}$ grains and the existence of a strong restraint surrounding the $\mathrm{Sr}-\mathrm{HT}$ grains from the glass-ceramic phase of gahnite also leads to the improvement in mechanical properties of the Sr-HT-G coating [36]. The coefficient of variant ( $\mathrm{CoV}=$ standard deviation divided by the mean) of the Sr-HT-G is coating slightly lower than that of the HAp coating, which are $16 \%$ and $20 \%$, respectively. The coating of Sr-HT-G has lower CoV values in microhardness because the Sr-HT-G coating possesses a more uniform microstructure compared to those in the HAp coating. The Weibull analysis of microhardness of the Sr-HT-G and HAp coatings are presented in Figure 6, where both coatings present good regression fits with $R^{2}$ values of 0.97 and 0.96 , respectively [41]. The Weibull moduli $\mathrm{m}$, which presents the scattering behavior of results within the distribution [41], show that both the Sr-HT-G and HAp coatings have low values of Weibull modulus but they are the typical values in thermal spray. The Sr-HT-G coating has a slightly higher value of Weibull moduli than the HAp coating, which indicates less variation in the microhardness results in the Sr-HT-G coating.

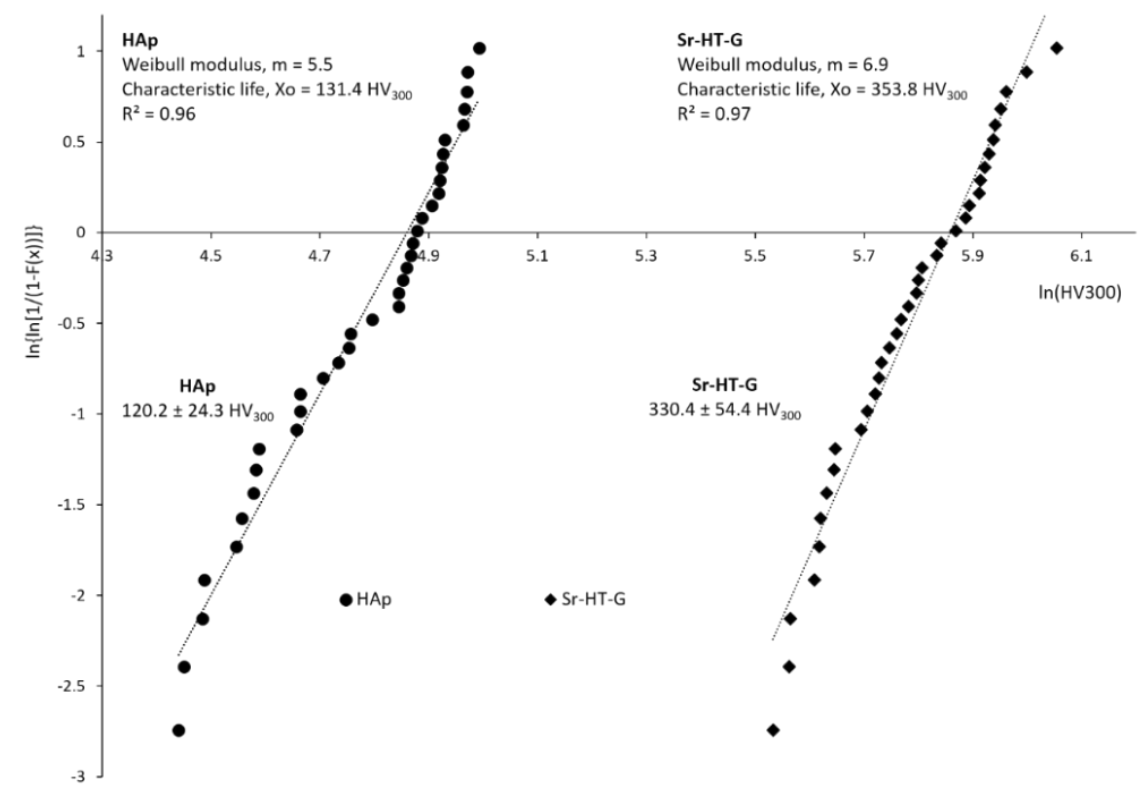

Figure 6. Weibull regression analysis of the Vickers hardness test of HAp and Sr-HT-G coatings.

\subsubsection{Nanohardness and Elastic Moduli}

The cross section of the Sr-HT-G coating shows a uniform structure in the coating, shown in Figure 7a. Figure 7b,d presents corresponding the SPM and SEM images of the same area after performing the nanoindentation. The indentation mapping results of the Sr-HT-G coating are presented by the distributions of elastic moduli and hardness in Figure $7 \mathrm{c}, \mathrm{e}$, respectively. The variant in the distributions of nanohardness and elastic moduli depends on the features of the selected area such as element compositions, phase structure, cracks, and pores. Generally, lower hardness and lower elastic moduli can be found in pore and crack areas [42]. Uniform distributions of nanohardness and elastic modulus can be achieved in the Sr-HT-G coating, which indicate the consistent of mechanical properties across the coating. This uniformity could be achieved by the presence of the gahnite phase in the coating that could enhance the mechanical properties across the coating [36]. 


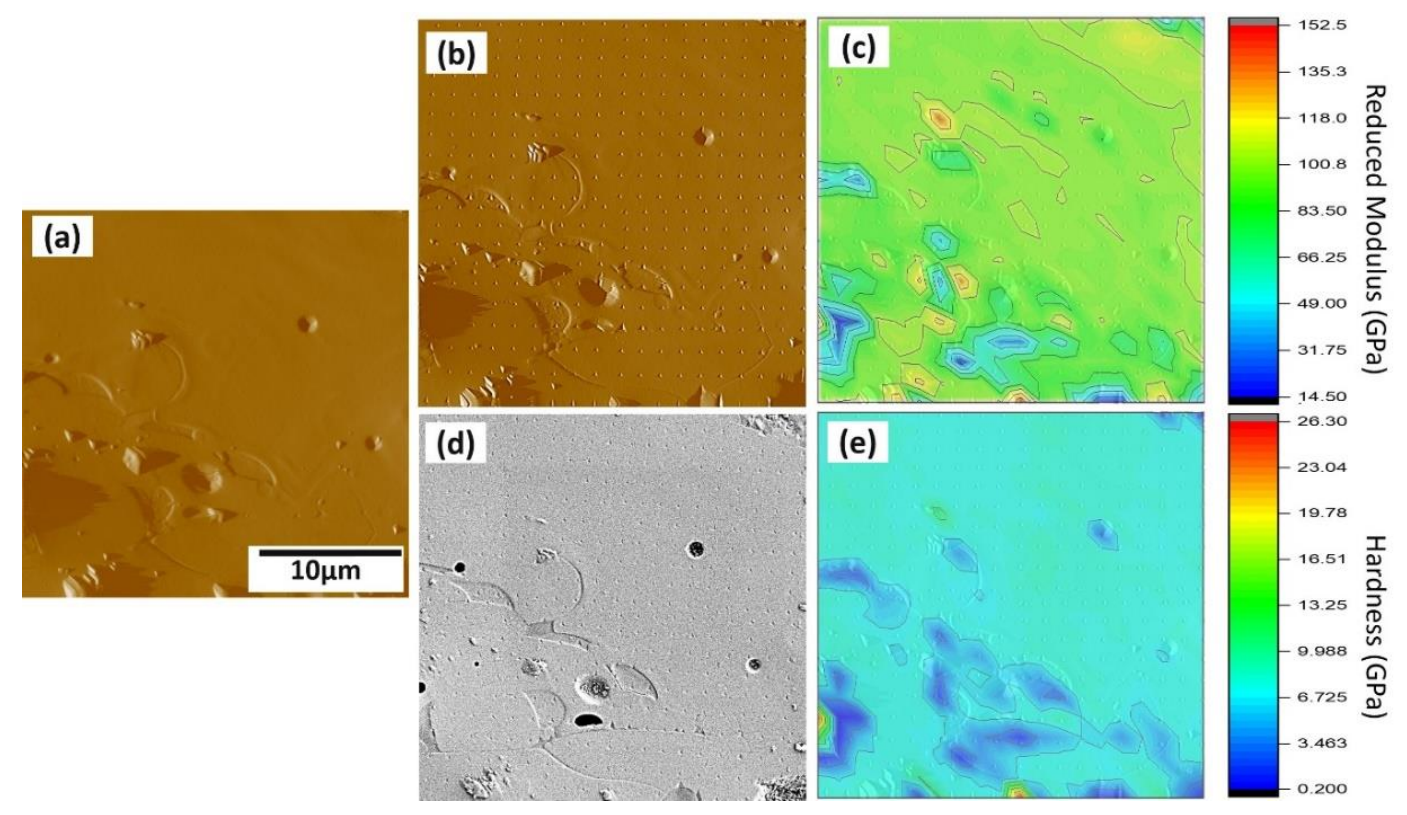

Figure 7. Results of the nanoindentation test of the Sr-HT-G coating. (a) The SPM image of surface before applying the indents; (b) and (d) the SPM and SEM image of surface after applying the indents; (c) and (e) property map of reduced modulus and hardness of the coating.

The distributions of nanohardness and elastic moduli in a selected area from the HAp coating are found in Figure 8. Similar to the testing procedure of the Sr-HT-G coating, Figure 8a presents a selected area that was pre-scanned to capture the features before performing the nanoindentation. After performing the nanoindentation, the surface was captured again via SPM and SEM techniques, which are shown in Figure $8 \mathrm{~b}, \mathrm{~d}$, respectively. The difference in contrast of the SEM image present different phases that have formed, which are named as " $\mathrm{A}$ " and " $\mathrm{B}$ " regions. The results of elastic moduli and nanohardness of the HAp coating are shown in Figure 8c,e in the form of distribution maps, respectively. The marks of indents in the HAp coating at the " $\mathrm{A}$ " area present deeper and larger sizes than those in the "B" area. Raman microspectroscopy was used to analyze the functional groups of the highlighted Region A and B of the HAp coating. It can be seen that both regions have same functional groups as the result of similar positions of Raman peaks in Figure 9. However, sharper peaks with higher intensity can be found in Region B, which indicates the formation of crystalline HAp while Region A presents the formation of an amorphous phase [43]. Similar to the study of J. Wen et al. [44], Region B yielded better mechanical properties, which it showed higher results of nanohardness and elastic moduli than Region A.

This indicates there is less uniformity of coating phases in the HAp coating when comparing with the Sr-HT-G coating. As the result, both nanohardness and elastic moduli showed high variants in distribution of values across the HAp coating. The average values of elastic moduli and nanohardness of the Sr-HT-G coating were $93.0 \pm 16.6$ and $7.2 \pm 2.1 \mathrm{GPa}$, respectively. On the other hand, lower results of both elastic modulus and nanohardness can be found in the HAp coating, which the average values were $77.6 \pm 41.5$ and $4.4 \pm 3.2 \mathrm{GPa}$, respectively. The average results of both nanohardness and elastic moduli in the Sr-HT-G coating showed significantly better results than that of the HAp coating, which were in accordance with the results in the Vickers microhardness tests. Furthermore, the Sr-HT-G coating presented lower values of $\mathrm{CoV}$ in both hardness and elastic moduli with $17.8 \%$ and $29.2 \%$, respectively, while these values of hardness and elastic moduli in the HAp coating were higher at $53.4 \%$ and $72.7 \%$ due to the lack of uniform phases. 


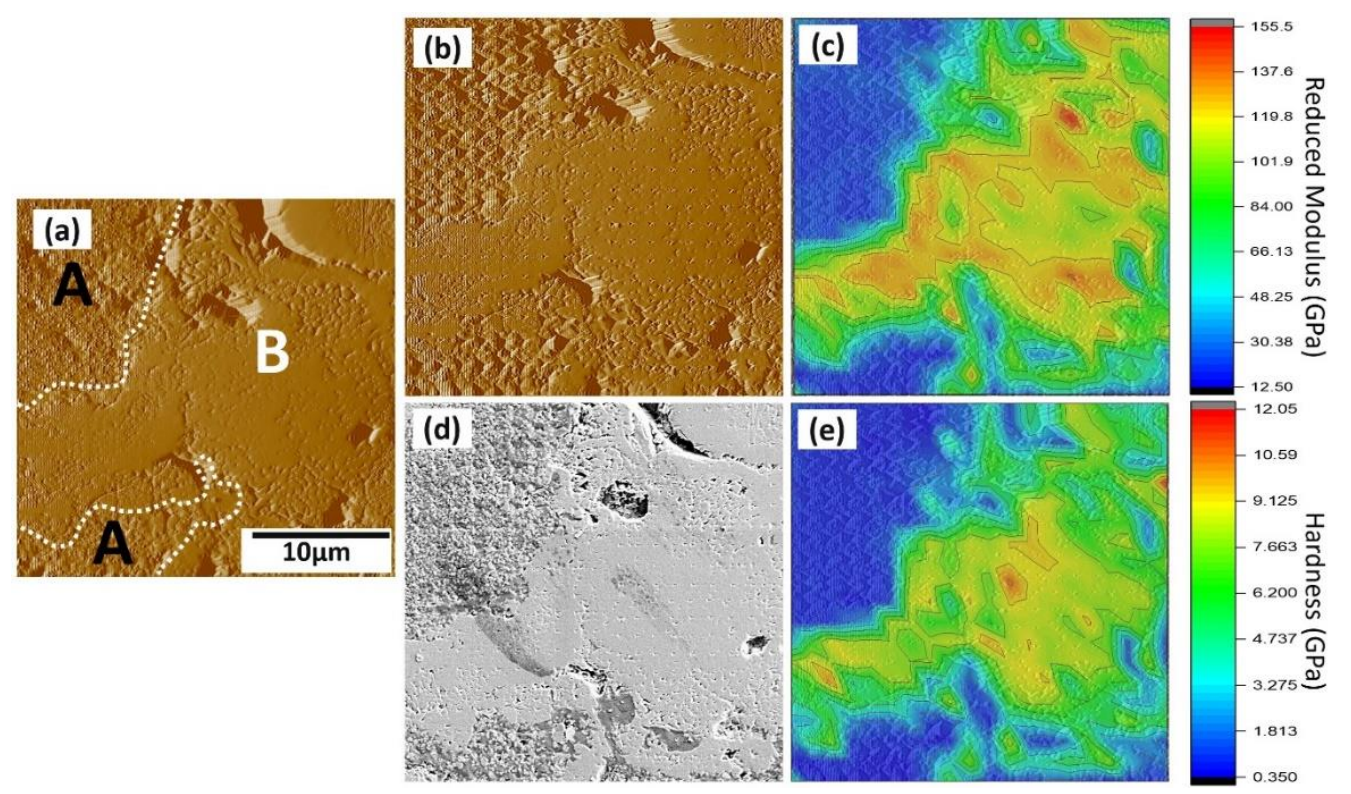

Figure 8. Results of the nanoindentation test of the HAp coating. (a) The SPM image of surface before applying the indents; (b) and (d) the SPM and SEM image of surface after applying the indents; (c) and (e) property map of reduced modulus and hardness of the coating.

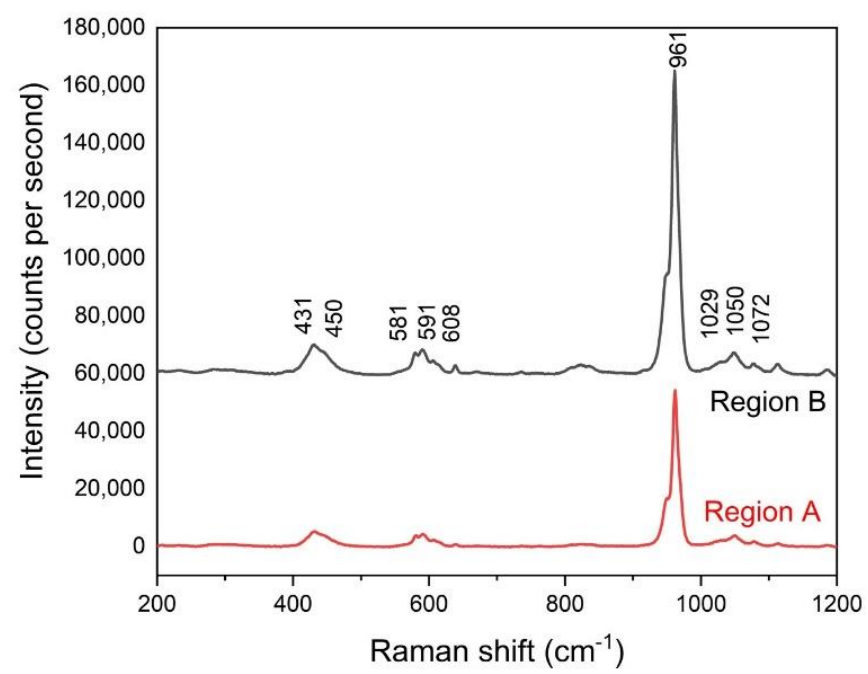

Figure 9. Raman microspectroscopy of the regions in the HAp coating.

\subsubsection{Nanoscratch and Nanoscanning Wear Performance}

Results of nanoscratch tests under the load of $1000 \mu \mathrm{N}$ are presented in Figure 10, where Figure 10a,d shows the surfaces of the selected areas after the scratching of Sr-HT-G and HAp coatings, respectively. It can be seen that the Sr-HT-G coating depicts tearing behavior only with shallow depths of penetration, while deeper and more plastic flow across the edge of the scratch direction can be found in the HAp coating. The 3D maps in Figure 10b,e render more details of the behavior of these coatings under scratch tests. The HAp coating experienced more plastic deformation with large pileup of materials that represents ploughing behavior under the scratch test. 

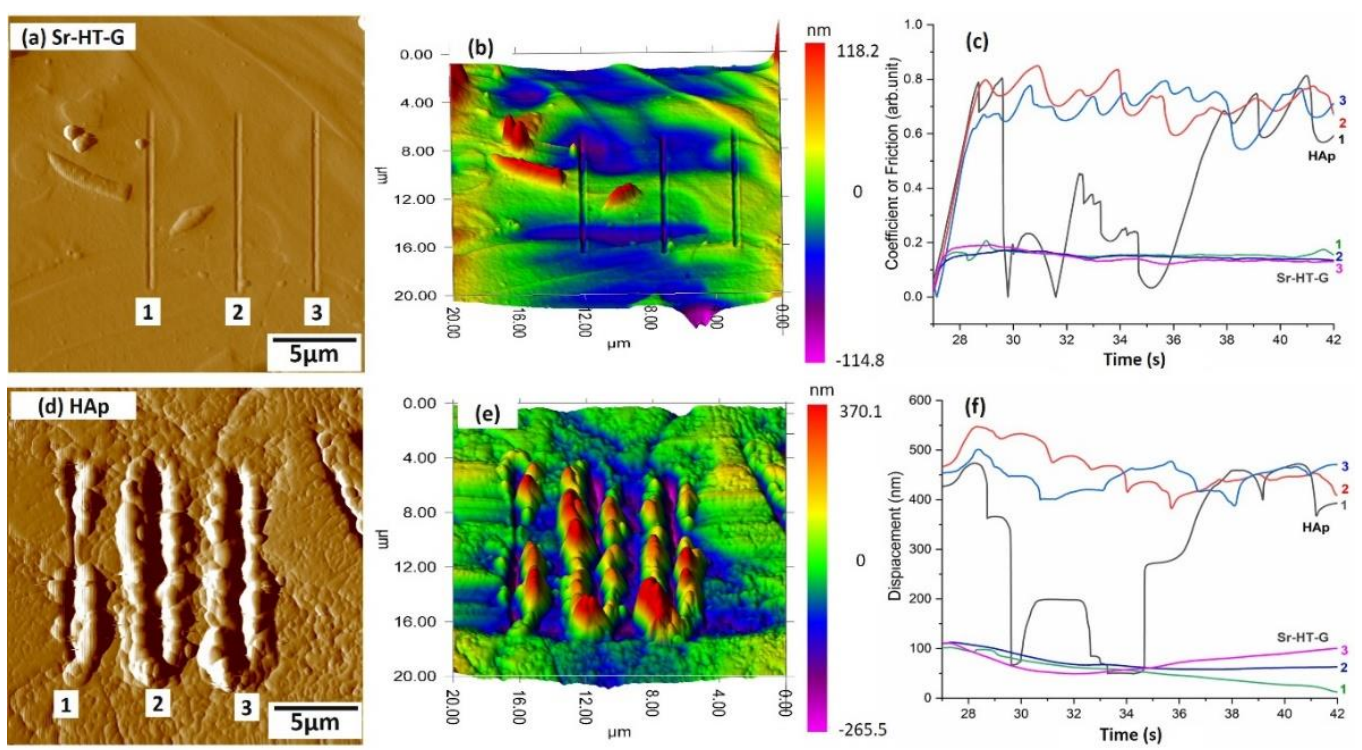

Figure 10. Nanoscratch test results of the Sr-HT-G coating $(\mathbf{a}, \mathbf{b})$; and the HAp coating $(\mathbf{d}, \mathbf{e})$; friction coefficient (c); and normal displacement (f).

Figure 10c, f reveals the coefficient of friction $(\mathrm{CoF})$ and depth of the scratch (displacement) of the Sr-HT-G and the HAp coatings, respectively, which show the details of Scratch 1, 2, and 3 from the Figure 10a,c. In the nanoscratch test, the actual applied load started from the 27th second to the 42nd second, while other times for loading and unloading periods are not considered. From the results of the nanoscratch tests, CoFs and displacements of the Sr-HT-G coating show high consistency with low values of CoFs and low penetration depths in all the scratches. On the other hand, CoF values and displacements in the HAp coating fluctuate continuously, i.e., values of $\mathrm{CoF}$ and displacement significantly decreased from 29.5 to $35 \mathrm{~s}$ in the scratches due to higher scratch resistance in this region of the HAp coating. This result could have originated from the significant difference in mechanical properties of different phases in the HAp coating, which has a similar trend with the distribution of hardness and elastic moduli.

The average depths of scratch are $60.9 \pm 9.7 \mathrm{~nm}(\mathrm{CoV}=16 \%)$ and $245.0 \pm 150.4 \mathrm{~nm}(\mathrm{CoV}=61 \%)$ for the Sr-HT-G and the HAp coatings, respectively. Lower scratch depth with less removal of materials in the Sr-HT-G coating indicate that the Sr-HT-G coating is more resistant to scratches. Furthermore, the average $\mathrm{CoF}$ of the $\mathrm{Sr}-\mathrm{HT}-\mathrm{G}$ coating is $0.14 \pm 0.02(\mathrm{CoV}=14 \%)$, which is much lower than the average $\mathrm{CoF}$ in the HAp coating, $0.69 \pm 0.14(\mathrm{CoV}=20 \%)$. Similar to the analysis in the nanoindentation, the lower result of $\mathrm{CoV}$ in the scratch test shows the coating microstructure of the Sr-HT-G coating presents more uniform features than the HAp coating. This results in the Sr-HT-G coating shows better scratch resistance than the HAp coating.

The wear behavior of the Sr-HT-G and the HAp coating under the applied load of $1000 \mu \mathrm{N}$ are presented in Figure 11, in which the pre-wear test, and post-wear test images were evaluated. The black square areas indicate the regions that were selected to perform nanowear tests. The surface before performing wear tests are presented in Figure 11a,d,g; while Figure 11b,e,h and Figure 11c,f,i illustrate the surface after the wear test of SPM images and their 3D views, respectively. Similar to the result from nanoindentation and nanoscratch tests, the Sr-HT-G coating presents uniform distribution with consistent results of wear volume in Figure $11 \mathrm{~b}$,c. On the other hand, the HAp coating reveals more variance of wear behavior due to a significant difference in the region of " $\mathrm{A}$ " and " $\mathrm{B}$ " as amorphous and crystalline regions, respectively, in Figure 11e,h. It can be seen that amorphous areas present less wear resistance than crystalline areas, showing similar trends in nanoindentation and nanoscratch tests. The wear volume for Sr-HT-G and HAp coatings are $0.11 \pm 0.03$ and $5.52 \pm 2.90 \mu \mathrm{m}^{3}$, respectively. This enhanced mechanical properties of the Sr-HT-G coating was achieved by doping zinc into a Ca-Si 
ceramic together with the formation of gahnite in the structure $[19,36]$. This result indicates that the Sr-HT-G coating possesses superior wear resistance than the HAp coating.
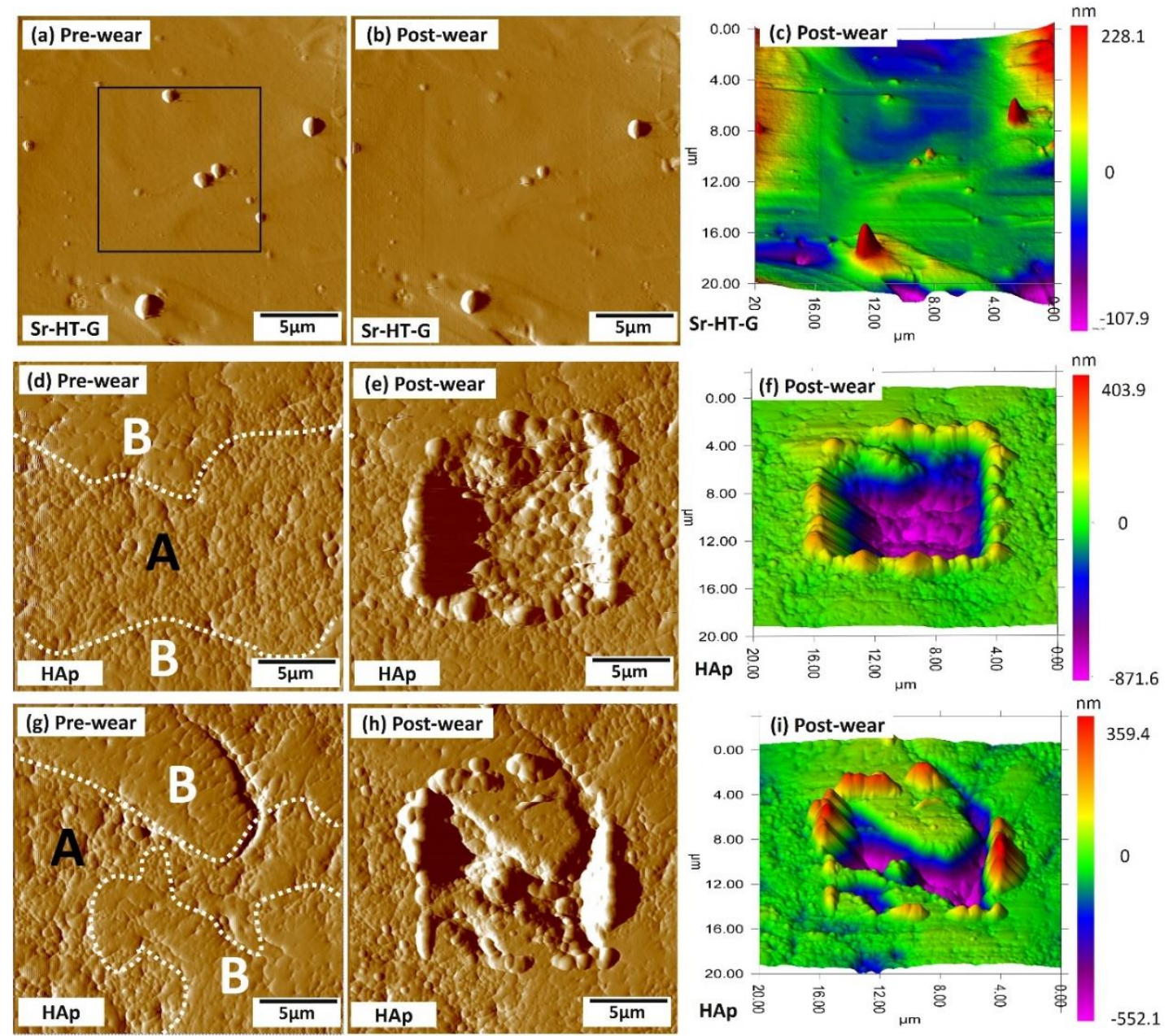

Figure 11. Nanowear test results of the Sr-HT-G coating $(\mathbf{a}-\mathbf{c})$ and the HAp coating $(\mathbf{d}-\mathbf{i})$.

\subsection{Results of Stem Cell Culture}

After cell culture for $24 \mathrm{~h}$, BMSC adhered on all the substrates indicating a good biocompatibility, which can be seen in Figure 12a. Cell density on Ti substrates was relatively higher than samples of the Sr-HT-G coating and the HAp coating in Figure 12b. In addition, BMSCs have a relatively larger cell spread on Ti substrates than that of the Sr-HT-G and HAp coatings, which can be seen in Figure 12c. This strong cell attachment on the Ti substrate is related to the differences in surface roughness profiles; both coatings had similar and higher surface roughness than the Ti. The surface roughness $\left(R_{\mathrm{a}}\right)$ of the Sr-HT-G coating and the HAp coating were $13.7 \pm 0.76$ and $10.2 \pm 0.7 \mu \mathrm{m}$, respectively; while the roughness of the as-receive Ti was about $0.1 \mu \mathrm{m}$. Nonetheless, the results indicate both coatings have good biocompatibility for BMSCs, in which the Sr-HT-G coating presented slightly higher cell density and spreading area of cell attachment compared to the HAp coating. 


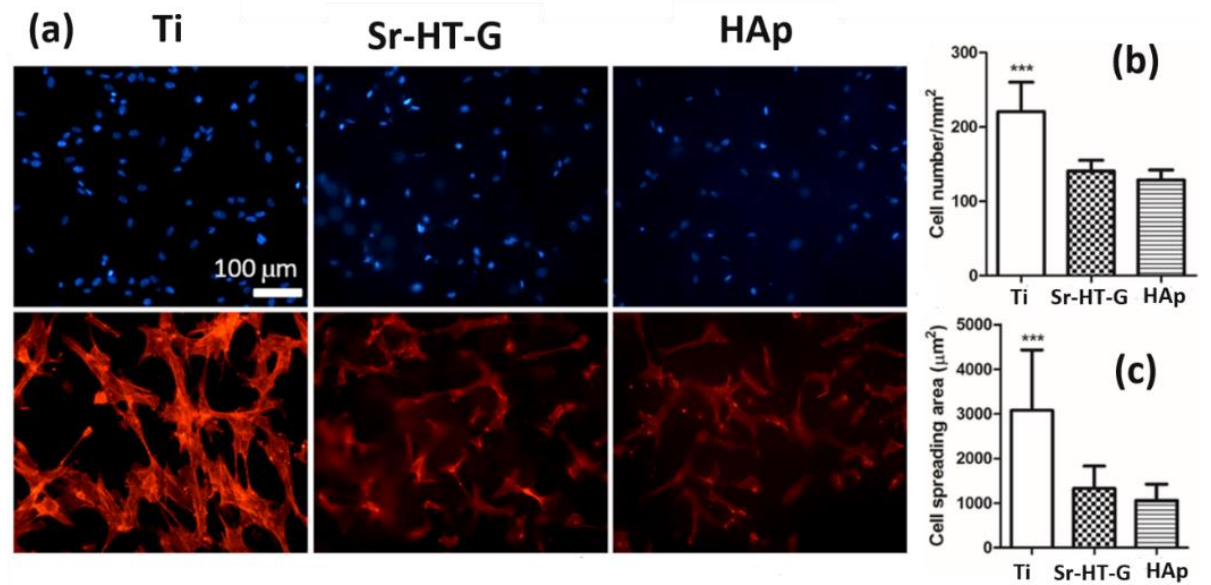

Figure 12. Biocompatibility tests of different substrates using bone marrow stem cells. (a) BMSC morphology on Ti, Sr-HT-G, and HAp surfaces. Cell nucleus (blue) and F-actin (red) were stained. (b) Cell density and (c) spreading area on various substrates. ${ }^{* *} p<0.01$ and ${ }^{* * *} p<0.001$ compared to Sr-HT-G and HAp surfaces.

\section{Conclusions}

The deposition of Sr-HT-G powders onto Ti-6Al-4V as a novel coating via an atmospheric plasma spray technique has demonstrated significant improvement in mechanical properties compared with the current commercial relevant hydroxyapatite coating. The Sr-HT-G coating showed more uniform microstructures with consistent distributions of hardness, elastic moduli, compared to the HAp coating. The as sprayed Sr-HT-G coating presented phases of Sr-HT and gahnite without formation of new phases. Vickers microhardness of the Sr-HT-G coating was significantly higher than results from the HAp coating; $330.4 \pm 54.4$ and $120.2 \pm 24.3$ HV300, respectively. Nanoindentation tests revealed consistent distributions of nanohardness and elastic moduli in the Sr-HT-G coating with the average values of $93.0 \pm 16.6$ and $7.2 \pm 2.1 \mathrm{GPa}$ for hardness and elastic moduli, respectively. On the contrary, the HAp coating showed lower and high variation in the distribution of hardness and elastic moduli, especially between the distinct areas of crystalline and amorphous phases. The nanohardness and elastic moduli of the HAp coating were $77.6 \pm 41.5$ and $4.4 \pm 3.2 \mathrm{GPa}$, respectively. The Sr-HT-G coating also showed better resistance to scratch and wear compared to the HAp coating under the same tests. In addition, the Sr-HT-G coating presented slightly higher density and spreading area of cell attachment in contrast to the HAp coating, indicating that the Sr-HT-G coatings possess good biocompatibility with good attachment of bone marrow mesenchymal stem cells. This study indicates that atmospheric plasma sprayed $\mathrm{Sr}-\mathrm{HT}-\mathrm{G}$ can be a viable approach for orthopaedic implants.

Author Contributions: Conceptualization, A.S., H.Z., C.C.B. and A.S.M.A.; methodology, D.Q.P., A.S.M.A. and C.C.B.; software, D.Q.P. and Y.-P.W.; validation, C.C.B., A.S.M.A. and H.Z.; formal analysis, D.Q.P.; investigation, D.Q.P.; resources, A.S., D.Q.P. and A.S.M.A.; data curation, D.Q.P., A.S.M.A.; writing-original draft preparation, D.Q.P., P.-Y.W.; writing—review and editing, D.Q.P., A.S.M.A., C.C.B. and P.-Y.W.; visualization, D.Q.P., A.S.M.A.; supervision, A.S.M.A., C.C.B., H.Z.; project administration, A.S.M.A., C.C.B.; funding acquisition, A.S., H.Z. and C.C.B.

Funding: This research is funded by the Centre for Innovative BioEngineering under the Industrial Transformation Training Centre (ITTC) scheme via the Australian Research Council (ARC) Award IC170100022. PYW thanks the support from the National Key Research and Development Program of China (2018YFC1105201), the National Natural Science Foundation of China, and the International cooperative research project of Shenzhen collaborative innovation program (20180921173048123).

Acknowledgments: The authors also would like to thank Deming Zhu for his assistance in operating the XPS and Andrew Moore for expert assistance in the preparation of samples. We deeply appreciate Ping Du from SIAT who performed the biocompatibility test.

Conflicts of Interest: The authors declare no conflict of interest. 


\section{References}

1. Wu, C.; Chang, J. A review of bioactive silicate ceramics. Biomed. Mater. 2013, 8, 032001. [CrossRef] [PubMed]

2. Park, J.B.; Bronzino, J.D. Biomaterials: Principles and Applications; CRC Press: Boca Raton, FL, USA, 2002. [CrossRef]

3. Dorozhkin, S.V.; Epple, M. Biological and medical significance of calcium phosphates. Angew. Chem. Int. Ed. 2002, 41, 3130-3146. [CrossRef]

4. Sun, L.; Berndt, C.C.; Gross, K.A.; Kucuk, A. Material fundamentals and clinical performance of plasma-sprayed hydroxyapatite coatings: A review. J. Biomed. Mater. Res. 2001, 58, 570-592. [CrossRef] [PubMed]

5. Hench, L.L. Biomaterials: A forecast for the future. Biomaterials 1998, 19, 1419-1423. [CrossRef]

6. Berndt, C.; Haddad, G.; Farmer, A.; Gross, K.A. Thermal spraying for bioceramic applications. Mater. Forum. 1990, 14, 161-173.

7. Dorozhkin, S.V. Bioceramics of calcium orthophosphates. Biomaterials 2010, 31, 1465-1485. [CrossRef]

8. Yao, H.-L.; Zou, Y.-L.; Bai, X.-B.; Wang, H.-T.; Ji, G.-C.; Chen, Q.-Y. Microstructures, mechanical properties and electrochemical behaviors of nano-structured HA/Ti composite coatings deposited by high-velocity suspension flame spray (HVSFS). Ceram. Int. 2018, 44, 13024-13030. [CrossRef]

9. Chen, X.; Zhang, B.; Gong, Y.; Zhou, P.; Li, H. Mechanical properties of nanodiamond-reinforced hydroxyapatite composite coatings deposited by suspension plasma spraying. Appl. Surf. Sci. 2018, 439, 60-65. [CrossRef]

10. Rauch, J.; Bolelli, G.; Killinger, A.; Gadow, R.; Cannillo, V.; Lusvarghi, L. Advances in high velocity suspension flame spraying (HVSFS). Surf. Coat. Technol. 2009, 203, 2131-2138. [CrossRef]

11. Tucker, R.C., Jr. ASM Handbook, Volume 05A-Thermal Spray Technology; ASM International: Materials Park, $\mathrm{OH}, \mathrm{USA}, 2013$. [CrossRef]

12. Sun, L. Thermal spray coatings on orthopedic devices: When and how the FDA reviews your coatings. J. Therm. Spray Technol. 2018, 27, 1280-1290. [CrossRef]

13. Schwarz, K. A bound form of silicon in glycosaminoglycans and polyuronides. Proc. Natl. Acad. Sci. USA 1973, 70, 1608-1612. [CrossRef] [PubMed]

14. Carlisle, E.M. Silicon: A possible factor in bone calcification. Science 1970, 167, 279. [CrossRef] [PubMed]

15. Hench, L.L. Bioceramics: From concept to clinic. J. Am. Ceram. Soc. 1991, 74, 1487-1510. [CrossRef]

16. Abe, Y.; Kokubo, T.; Yamamuro, T. Apatite coating on ceramics, metals and polymers utilizing a biological process. J. Mater. Sci. Mater. Med. 1990, 1, 233-238. [CrossRef]

17. Liu, X.; Tao, S.; Ding, C. Bioactivity of plasma sprayed dicalcium silicate coatings. Biomaterials 2002, 23, 963-968. [CrossRef]

18. Ni, S.; Chang, J.; Chou, L.; Zhai, W. Comparison of osteoblast-like cell responses to calcium silicate and tricalcium phosphate ceramics in vitro. J. Biomed. Mater. Res. Part B Appl. Biomater. 2007, 80, 174-183. [CrossRef]

19. Zreiqat, H.; Ramaswamy, Y.; Wu, C.; Paschalidis, A.; Lu, Z.; James, B.; Birke, O.; McDonald, M.; Little, D.; Dunstan, C.R. The incorporation of strontium and zinc into a calcium-silicon ceramic for bone tissue engineering. Biomaterials 2010, 31, 3175-3184. [CrossRef]

20. Iimori, Y.; Kameshima, Y.; Okada, K.; Hayashi, S. Comparative study of apatite formation on $\mathrm{CaSiO}_{3}$ ceramics in simulated body fluids with different carbonate concentrations. J. Mater. Sci. Mater. Med. 2005, 16, 73-79. [CrossRef]

21. Wu, C.; Chang, J.; Zhai, W. A novel hardystonite bioceramic: Preparation and characteristics. Ceram. Int. 2005, 31, 27-31. [CrossRef]

22. Roohani-Esfahani, S.I.; Dunstan, C.R.; Li, J.J.; Lu, Z.; Davies, B.; Pearce, S.; Field, J.; Williams, R.; Zreiqat, H. Unique microstructural design of ceramic scaffolds for bone regeneration under load. Acta Biomater. 2013, 9 , 7014-7024. [CrossRef]

23. Wang, G.; Roohani-Esfahani, S.-I.; Zhang, W.; Lv, K.; Yang, G.; Ding, X.; Zou, D.; Cui, D.; Zreiqat, H.; Jiang, X. Effects of Sr-HT-Gahnite on osteogenesis and angiogenesis by adipose derived stem cells for critical-sized calvarial defect repair. Sci. Rep. 2017, 7, 41135. [CrossRef] [PubMed] 
24. Li, J.J.; Dunstan, C.R.; Entezari, A.; Li, Q.; Steck, R.; Saifzadeh, S.; Sadeghpour, A.; Field, J.R.; Akey, A.; Vielreicher, M.; et al. A novel bone substitute with high bioactivity, strength, and porosity for repairing large and load-bearing bone defects. Adv. Healthc. Mater. 2019, 8, e1801298. [CrossRef] [PubMed]

25. Sun, L.; Berndt, C.C.; Grey, C.P. Phase, structural and microstructural investigations of plasma sprayed hydroxyapatite coatings. Mater. Sci. Eng. A 2003, 360, 70-84. [CrossRef]

26. ASTM-E1920-03. Standard Guide for Metallographic Preparation of Thermal Sprayed Coatings; ASTM International: West Conshohocken, PA, USA, 2014.

27. Pham, D.Q.; Berndt, C.C.; Gbureck, U.; Zreiqat, H.; Truong, V.K.; Ang, A.S.M. Mechanical and chemical properties of Baghdadite coatings manufactured by atmospheric plasma spraying. Surf. Coat. Technol. 2019, 378, 124945. [CrossRef]

28. Oliver, W.C.; Pharr, G.M. An improved technique for determining hardness and elastic modulus using load and displacement sensing indentation experiments. J. Mater. Res. 1992, 7, 1564-1583. [CrossRef]

29. Berndt, C.C.; Hasan, F.; Tietz, U.; Schmitz, K.P. A review of hydroxyapatite coatings manufactured by thermal spray. In Advances in Calcium Phosphate Biomaterials; Ben-Nissan, B., Ed.; Springer: Berlin/Heidelberg, Germany, 2014; pp. 267-329. [CrossRef]

30. Gross, K.A.; Berndt, C.C.; Herman, H. Amorphous phase formation in plasma-sprayed hydroxyapatite coatings. J. Biomed. Mater. Res. 1998, 39, 407-414. [CrossRef]

31. Najafinezhad, A.; Abdellahi, M.; Ghayour, H.; Soheily, A.; Chami, A.; Khandan, A. A comparative study on the synthesis mechanism, bioactivity and mechanical properties of three silicate bioceramics. Mater. Sci. Eng. C 2017, 72, 259-267. [CrossRef]

32. Levingstone, T.J.; Ardhaoui, M.; Benyounis, K.; Looney, L.; Stokes, J.T. Plasma sprayed hydroxyapatite coatings: Understanding process relationships using design of experiment analysis. Surf. Coat. Technol. 2015, 283, 29-36. [CrossRef]

33. Strohmeier, B.R. Zinc Aluminate $\left(\mathrm{ZnAl}_{2} \mathrm{O}_{4}\right)$ by XPS. Surf. Sci. Spectra 1994, 3, 128-134. [CrossRef]

34. Strohmeier, B.R.; Hercules, D.M. Surface spectroscopic characterization of the interaction between zinc ions and $\gamma$-alumina. J. Catal. 1984, 86, 266-279. [CrossRef]

35. Moulder, J.F.; Stickle, W.F.; Sobol, P.E. Handbook of X-ray Photoelectron Spectroscopy: A Reference Book of Standard Spectra for Identification and Interpretation of XPS Data; Physical Electronics, Inc.: Eden Prairie, MN, USA, 1995.

36. Zreiqat, H.; Roohani-Esfahani, S.-I.; Dunstan, C.; Li, J.J. Biocompatible Material and Uses Thereof. U.S. Patent No. US 9,220,806 B2, 29 December 2015.

37. Demri, B.; Muster, D. XPS study of some calcium compounds. J. Mater. Process. Technol. 1995, 55, 311-314. [CrossRef]

38. Ang, A.S.M.; Berndt, C.C. A review of testing methods for thermal spray coatings. Int. Mater. Rev. 2014, 59, 179-223. [CrossRef]

39. Madejski, J. Solidification of droplets on a cold surface. Int. J. Heat Mass Transf. 1976, 19, $1009-1013$. [CrossRef]

40. Gross, K.A.; Saber-Samandari, S.; Heemann, K.S. Evaluation of commercial implants with nanoindentation defines future development needs for hydroxyapatite coatings. J. Biomed. Mater. Res. Part B Appl. Biomater. 2010, 93, 1-8. [CrossRef]

41. Lin, C.K.; Berndt, C.C. Statistical analysis of microhardness variations in thermal spray coatings. J. Mater. Sci. 1995, 30, 111-117. [CrossRef]

42. Deram, V.; Minichiello, C.; Vannier, R.N.; Le Maguer, A.; Pawlowski, L.; Murano, D. Microstructural characterizations of plasma sprayed hydroxyapatite coatings. Surf. Coat. Technol. 2003, 166, 153-159. [CrossRef]

43. De Grauw, C.; de Bruijn, J.; Otto, C.; Greve, J. Investigation of bone and calcium phosphate coatings and crystallinity determination using Raman microspectroscopy. Cells Mater. 1996, 6, 6.

44. Wen, J.; Leng, Y.; Chen, J.; Zhang, C. Chemical gradient in plasma-sprayed HA coatings. Biomaterials 2000, 21, 1339-1343. [CrossRef]

(C) 2019 by the authors. Licensee MDPI, Basel, Switzerland. This article is an open access article distributed under the terms and conditions of the Creative Commons Attribution (CC BY) license (http://creativecommons.org/licenses/by/4.0/). 